\title{
The potential of biochar and modified kaolinite composites for chromium immobilization and its uptake by Spinacia oleracea $\mathbf{L}$. from chromium contaminated soil
}

\author{
HAFIZ MUHAMMAD TAUQEER ${ }^{1 *}$, \\ MUHAMMAD IQBAL $^{2}$, ALI KHAN \\ SHAHBAZ $^{2}$
}

${ }^{1}$ Department of Environmental Sciences, University of Gujrat, Hafiz Hayat Campus, Gujrat 50700, Pakistan. Email address: enviro1537@gmail.com

${ }^{2}$ Department of Environmental Sciences and Engineering,

Government College University, Faisalabad, 38000, Pakistan.

The applications of tannery wastewater significantly contaminated farmlands with chromium $(\mathrm{Cr})$ and have been recognized as an environmental issue due to its bioaccumulation in crops and vegetables. Thus, there is a need to take remedial measures to reduce its bioavailability to crops grown on them. An experiment was conducted to explore the efficiency of coconut-shell biochar and modified kaolinite composites for Cr immobilization and subsequently, its uptake by Spinacia oleracea.To achieve this aim, first, kaolinite was modified by heating $\left(450{ }^{\circ} \mathrm{C}\right)$ it and the biochar prepared by pyrolyzing the coconut-shell at $450{ }^{\circ} \mathrm{C}$, respectively. A suspension of kaolinite (with and without heating) was prepared by dissolving it in deionized water. The biochar was dipped into the suspension of kaolinite (with and without heating) and stirred for two hours. The soil was spiked with $120 \mathrm{mg} \mathrm{kg}^{-1} \mathrm{Cr}$ by using $\mathrm{K}_{2} \mathrm{Cr}_{2} \mathrm{O}_{7}$. Later, the spiked soil was amended with biochar and kaolinite composites and $S$. oleracea subjected to grow for 120 days. The treatments deployed in this study are control, BCHR, SK (simple kaolinite without heating), MKC (modified kaolinite clay), $\mathrm{BCHR}+\mathrm{SK}$ and $\mathrm{BCHR}+\mathrm{MKC}$. The results revealed that the $\mathrm{BCHR}+\mathrm{MKC}$ treatment significantly improved $S$. oleracea biomass and reduced $\mathrm{Cr}$ concentrations in roots over control. Furthermore, significantly the highest increase in the activities of antioxidants was recorded in $\mathrm{BCHR}+\mathrm{MKC}$ and BCHR treatments over control. Our results conclude that biochar and kaolinite composites are suitable amendments in reducing $\mathrm{Cr}$ phytotoxicity.

Key words: Antioxidants, Biochar, chromium, immobilization, kaolinite, soil 